\title{
Review Article \\ Heterocyclic Aromatic Amines Heterocomplexation with Biologically Active Aromatic Compounds and Its Possible Role in Chemoprevention
}

\author{
Anna Woziwodzka, Grzegorz Gołuński, and Jacek Piosik \\ Laboratory of Biophysics, Intercollegiate Faculty of Biotechnology UG-MUG, Kładki 24, 80-822 Gdańsk, Poland \\ Correspondence should be addressed to Jacek Piosik; piosik@biotech.ug.gda.pl
}

Received 29 January 2013; Accepted 24 March 2013

Academic Editors: L. Loura, M. P. Ponomarenko, M. Ruiz-Gómez, and S. Taneva

Copyright (C) 2013 Anna Woziwodzka et al. This is an open access article distributed under the Creative Commons Attribution License, which permits unrestricted use, distribution, and reproduction in any medium, provided the original work is properly cited.

Food-borne heterocyclic aromatic amines (HCAs) are known mutagens and carcinogens present especially in Western population diet, which contains large amount of meat and its products. HCAs are capable of interacting with DNA directly through the formation of covalent adducts, however this process requires biological activation in liver, mainly by cytochrome P450 enzymes. This process may produce mutations and in consequence may contribute to the development of cancer. However, there are many studies showing that several biologically active aromatic compounds (BACs) may protect against genotoxic effects of HCAs. Direct interactions and noncovalent heterocomplexes formation may be one of the most important mechanisms of such protection. This work describes several BACs present in human diet, which are capable of molecular complexes formation with HCAs and protect cells as well as whole organisms against HCAs action.

\section{Introduction}

Several human mutagens and carcinogens belong to aromatics. Polycyclic hydrocarbons (PAHs), aflatoxins, ethidium bromide, acridine dyes such as ICR170 and ICR191, anticancer drugs: daunomycin, doxorubicin, and mitoxantrone, and food-derived heterocyclic aromatic amines (HCAs) can serve as examples. Among them, vast attention is paid to HCAs, which might be responsible for the increase in gastrointestinal tract cancers, observed particularly in Western diet populations with high meat intake (Figure 1).

The mutagenic activity of thermally processed meat was firstly observed in 1939 [1] and subsequently in the late 1970s [2]. These observations led to the isolation and characterization of a new class of potent food-borne mutagens/carcinogens, heterocyclic aromatic amines (HCAs) [3]. Basing on their structures, HCAs can be divided into two classes [4]. 2-Amino-3-methylimidazo[4,5-f] quinoline (IQ-) type HCAs are produced during heat processing of creatine/creatinine, sugars, and free amino acids mixtures in temperatures below $300^{\circ} \mathrm{C}$ in the Maillard reaction. The second class, non-IQ-type HCAs, are formed at higher temperatures, above $300^{\circ} \mathrm{C}$ by pyrolysis of amino acids and proteins. All HCAs have at least one aromatic and one heterocyclic ring in their structure.

HCAs are potent mutagens in the Salmonella/reversion assay as well as proven carcinogens in laboratory animals, producing multiorgan tumors, for example, in the colon, mammary glands, and prostate [5]. Moreover, a close relationship between consumption of thermally processed protein-rich food (mainly meat and fish) and cancer occurrence has been observed in many studies [6-9], indicating a significant role of HCAs in human carcinogenesis.

It is believed that HCAs exhibit mutagenic/carcinogenic activity only after their metabolic activation, involving phase I $N$-hydroxylation by different isoenzymes of cytochrome P450 (mainly CYP1A2) and phase II esterification of the exocyclic amino group. Products of both phase I and II activation can be spontaneously converted to arylnitrenium ions $\left(\mathrm{R}^{-\mathrm{NH}^{+}}\right)$, capable of forming covalent adducts with DNA [10].

HCAs are considered as important factors in a lifestyleconnected carcinogenesis, according to IARC classified as 
<smiles>Cn1c(N)nc2c3cccnc3ccc21</smiles>

IQ<smiles>CN1C(N)=NC2N=CC(c3ccccc3)=CC21</smiles>

$\mathrm{PhIP}$<smiles>Cc1cc2ncccc2c2nc(N)n(C)c12</smiles>

MeIQ<smiles>Cc1nc(N)cc2[nH]c3ccccc3c12</smiles>

Trp-P-2<smiles>Cc1cnc2ccc3c(nc(N)n3C)c2c1</smiles>

MeIQx<smiles>Cc1cccn2c1nc1ccc(N)nc12</smiles>

Glu-P-1

FIGURE 1: Examples of heterocyclic aromatic amines (HCAs) chemical structures. IQ: 2-amino-3-methylimidazo[4,5- $f$ ]quinoline; MeIQ: 2-amino-3,4-dimethylomidazo[4,5-f] quinoline; MeIQx: 2-amino-3,8-dimethylimidazo[4,5-f]quinoxaline; PhIP: 2-amino-1-methyl6-phenylimidazo[4,5-b]pyridine; Trp-P-2: 3-amino-1-methyl-5H-pyrido[4,3-b]indole; Glu-P-1: 2-amino-6-methyldipyrido[1,2- $a$ : $3{ }^{\prime}, 2^{\prime}$ d]imidazole.

2A/B carcinogens $[11,12]$, therefore being extensively investigated worldwide with a particular interest in finding methods to diminish their genotoxic potential. As a result, numerous studies concerning protective effects of several dietary components against HCAs mutagenic and carcinogenic activity have been performed. It is estimated that approximately 600 different individual compounds as well as complex mixtures have been described as antimutagenic or anticarcinogenic towards HCAs, representing diverse modes of action [13]. Proposed mechanisms of protection involve inhibition of mutagen formation, inhibition of HCAs activating enzymes, induction of HCAs detoxifying enzymes, electrophile-scavenging, enhanced DNA repair, alteration of signaling pathways involved in apoptosis and proliferation, and direct binding of HCAs and their metabolites by interceptor molecules [14].

In the studies concerning the molecular mechanisms of chemoprevention against HCAs activity observed for several food components, the main focus is placed on the interaction of these compounds with different metabolic pathways of HCAs, with protective effects resulting from reduction in HCAs bioactivation and/or enhancement of their detoxication. Nevertheless, taking into consideration that many natural protective compounds have aromatic moieties in their structure, it seems possible that noncovalent direct interactions, especially stacking $(\pi-\pi)$ complexes formation between protective molecules and HCAs, can, at least in part, contribute to the observed chemopreventive effects. Such sequestration of mutagen molecules in heterocomplexes with biologically active aromatic compounds (BACs) can reduce their bioavailability and in consequence effectively prevent from their genotoxic effects (Figure 2).

This paper summarizes the current state of knowledge on the importance of heterocomplexation in diminishing various biological effects of HCAs.

\section{Mechanism of Heterocomplexation}

Mechanism of small aromatic molecules protective action against HCAs activity is often attributed to their ability to form heterocomplexes between these compounds. Formation of such complexes is dependent on hydrophobic interactions between $\pi-\pi$ electron systems from overlapping aromatic rings present in both molecules. The ability of stacking heterocomplexes formation can be described by several biophysical parameters, such as enthalpy changes $(\Delta H)$ or association constants (e.g., neighborhood association constant, $K_{\mathrm{AC}}$ ). For example, calculated values of neighborhood association constants $\left(K_{\mathrm{AC}}\right)$ for HCAs-theophylline complex formation are greater than $K_{\mathrm{AC}}$ values of HCAs-caffeine and HCAs-pentoxifylline heterocomplexes [15]. Andrejuk et al. reported similar relationship between association constant values of heterocomplexes formation for several aromatic compounds and theophylline and other methylxanthines [16]. This difference was interpreted as a consequence of a 7-Me group absence in theophylline molecules, which is present in caffeine and can introduce steric hindrance, reducing heterocomplexation possibility [16]. Possibility of high-order complex formation can be considered as another reason for differences between association constants values of stacking complexes formation. Formation of such high-order complexes was proposed previously for the interaction between caffeine (CAF) and anticancer drug mitoxantrone (MIT) [17]. The authors suggested that the formation of MIT-(CAF) $)_{2}$ complex is more probable and more thermodynamically favorable than $1: 1$ heterocomplex, as concluded from lower values of enthalpy changes for 2:1 heterocomplexes [17]. Apart from stacking complexes formation, direct binding of mutagen to inhibitor molecules can involve electrostatic and $\mathrm{H}$-bond interactions, which can act independently or additionally to heterocomplexes 


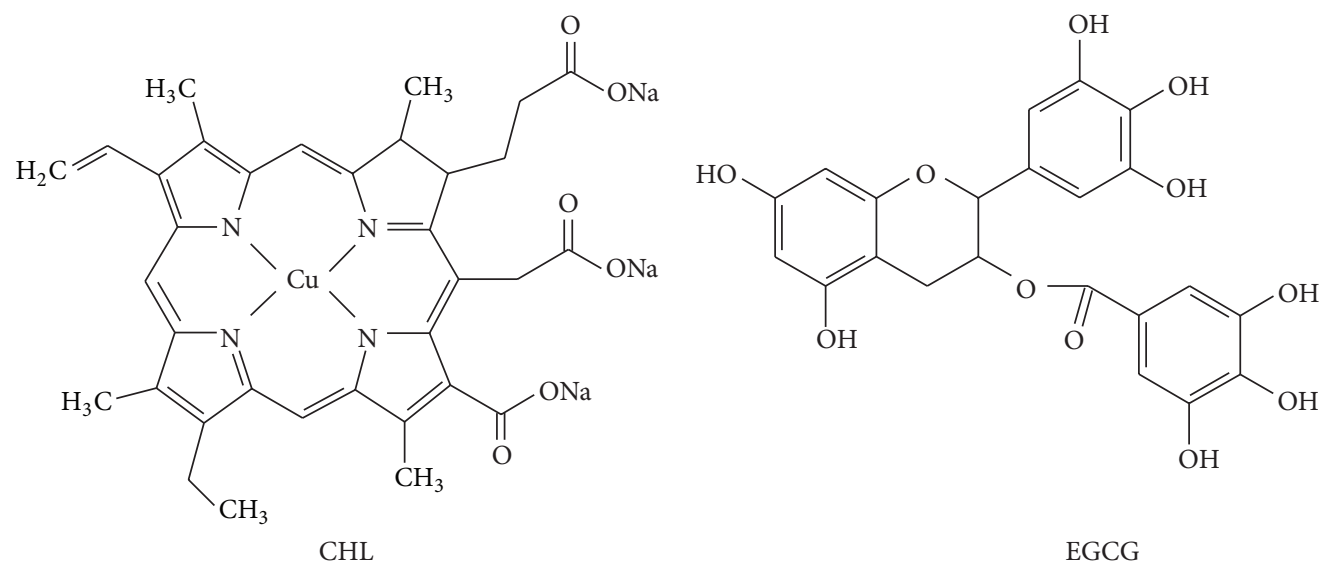<smiles>CN1CNc2c1c(=O)n(C)c(=O)n2C</smiles>

CAF<smiles>O=c1cc(-c2ccc(O)cc2)oc2cc(O)cc(O)c12</smiles>

Apigenin

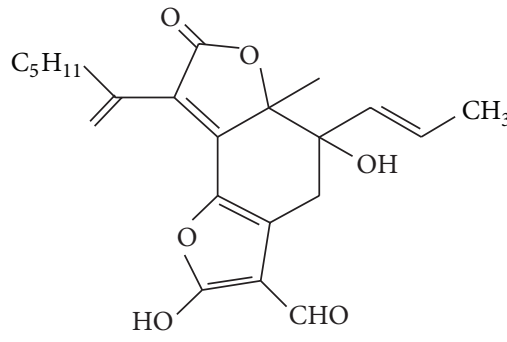

Xanthomonasin A

FIGURE 2: Examples of biologically active aromatic compounds (BACs) chemical structures. CHL: chlorophyllin; EGCG: (-)-epigallocatechin gallate; CAF: caffeine.

formation, stabilizing/promoting $\pi-\pi$ interactions by facilitation of two molecules docking. Semenov et al. suggested that stacking heterocomplexes may be stabilized by intermolecular hydrogen bonds formation, which were demonstrated using vibrational spectroscopy for flavin-mononucleotide interactions with ethidium bromide and proflavine [18]. All above-mentioned factors may influence the ability of several aromatic compounds to form stacking heterocomplexes with HCAs.

There are two possible mechanisms describing how formation of stacking heterocomplexes between small aromatic molecules can modulate their biological activity. First of all, formation of heterocomplexes between HCAs and several aromatic compounds can decrease concentration of free, biologically active form of HCAs, thus diminishing their biological activity. This mechanism of protection is known as "interceptor" mode of CAF and other methylxanthines action and was proposed by Bedner et al. [19]. The "interceptor" mode of CAF was described and analyzed for HCAs [15] and several other aromatic compounds: ethidium bromide [20, $21]$, propidium iodide $[19,20]$, quinacrine mustard, ICR170, ICR191 [22], proflavine [23], and several anticancer drugs [17, $24,25]$. Similar mechanism was also described for interaction of chlorophyllin (CHL) [26] and other natural constituents of human diet [27] with several aromatic compounds. It was demonstrated that $\mathrm{CHL}$ forms stacking heterocomplexes with HCAs and in consequence diminishes their mutagenic activity and reduces their absorption from gastrointestinal tract $[28,29]$. The second proposed mechanism of CAF and other aromatic compounds protective action is defined as "protector" mode of action [19]. According to this mechanism, CAF may intercalate to DNA and compete with mutagen for free binding sites [21, 23]. However, "protector" mode of CAF or other aromatic compounds towards HCAs seems unlikely, because biologically activated HCAs form covalent adducts rather than intercalate to DNA [30, 31].

\section{Role of Chlorophyllin (CHL) and Other Porphyrins}

Chlorophyllin (CHL) is a water-soluble salt of chlorophyll containing a chelated copper or sodium ion. CHL is undoubtedly one of the best-studied interceptor molecules, which can effectively reduce the activity of several aromatic mutagens and carcinogens, such as PAHs, aflatoxin $\mathrm{B}_{1}(\mathrm{AFB1})$, and HCAs [32]. Its protective activity is often attributed to its ability to form stacking heterocomplexes with planar aromatic mutagens, which can diminish their bioavailability and therefore protect against their biological effects.

3.1. Direct Interactions between HCAs and CHL. UV-vis spectroscopy studies demonstrated that CHL forms molecular complexes with IQ with 2:1 stoichiometry and dissociation constant $K_{S}=0.141 \pm 0.028 \mathrm{mM}$ determined from the Benesi-Hildebrand plot [33]. Moreover, CHL was proven to inhibit mutagenic activity of a broad range of IQ-type and non-IQ-type HCAs in short-term genotoxicity 
assays [29]. Direct interactions between CHL and HCAs were examined spectrophotometrically, with binding constants $K_{b}$ determined from Benesi-Hildebrand plot ranging from $3.07 \cdot 10^{3} \mathrm{M}^{-1}$ to $12.74 \cdot 10^{3} \mathrm{M}^{-1}$ and $2: 1$ and $1: 1$ stoichiometries of CHL-mutagen complexes formation for IQ-type and nonIQ-type HCAs, respectively. Observed protective effects of CHL against HCAs mutagenic activity were markedly correlated with strength of mutagen-CHL complex formation, reflected by appropriate binding constant values. These findings support the hypothesis that interception of aromatic mutagen molecules in noncovalent molecular complexes with CHL can be considered as an effective mechanism for CHL protective action, especially for the systems where interceptor molecules can reach concentrations significantly higher than possible mutagen concentrations. Further studies employing molecular modeling analyses of IQ- and nonIQ-type HCA interactions with CHL and its structurally related porphyrin derivatives revealed that two factors contribute to the molecular complex formation [34]. Firstly, an exocyclic amine group present in HCA can interact with acid groups on CHL and other porphyrins. Replacement of an amine group with a nitro group in $\mathrm{NO}_{2}$ IQ resulted in its very weak interaction with $\mathrm{CHL}$ (binding constant $K_{b}$ estimated at $<0.5 \cdot 10^{3} \mathrm{M}^{-1}$ ) and was accompanied with a lack of antimutagenic activity of CHL towards nitro-IQ [29]. Secondly, stacking $(\pi-\pi)$ interactions between overlapping aromatic rings is crucial for stable interactions between HCAs and porphyrin derivatives. The presence of methyl groups in chlorophyll derivatives, which can possibly introduce steric hindrance and thus interfere with $\pi-\pi$ interactions, was shown to increase the minimal energies of the interactions [34]. At the same time, the authors noticed that many of the interceptor molecules, apart from heterocomplexation with aromatic mutagens, are likely to interact with each other, forming dimers or longer homoaggregates. This effect can complicate the quantitative analysis of the experimental system, as the fraction of the free/bound interceptor cannot be directly associated with the amount of added mutagen. This problem can be overcome by using thermodynamical models of mixed aggregation, which allow for infinite homo- and heterocomplexation between interacting aromatic molecules and enable one not only to calculate binding constants, that is, neighborhood association constants, but also to determine concentrations of each possible component of every analyzed mutagen-interceptor mixture. Such approach was successfully applied for interaction analyses of HCAs [15] and other aromatic molecules $[22,35,36]$ with caffeine and other methylxanthines and will be discussed in detail in the next section of this paper.

3.2. Interception and Other Mechanisms of CHL Action. Although vast majority of studies concerning $\mathrm{CHL}$ as a chemoprotective agent indicate that $\mathrm{CHL}$ acts as an "interceptor" molecule, forming heterocomplexes with several planar mutagens, there are some papers describing different modes of CHL antimutagenic and anticarcinogenic activity. Yun et al. [37] suggested that CHL can inactivate cytochrome P450 (CYP) involved in the bioactivation of many environmental and food-borne mutagens, whereas Tachino et al. [38] pointed out antioxidant and free radical scavenging effects of CHL and increased mutagen degradation rates in the presence of CHL. These alternative mechanisms of CHL action can explain its protective effects towards nonaromatic compounds, such as alkylating agents: methyl methanesulfonate (MMS), methylnitrosourea (MNU), ethylnitrosourea (ENU) [39, 40], or radiationinduced DNA damage $[41,42]$. Moreover, influence of CHL on phase II hepatic enzymes was proposed as a mode of CHL protective action against low doses of PhIP in rats [43].

On the other hand, CHL was demonstrated to protect against mutagenic activity of direct-acting $N$-hydroxy HCAs derivatives: Trp-P-2[NHOH] [44], N-OH-IQ [45], and other direct-acting aromatic compounds: benzo[a]pyrene-7,8-diol9,10-epoxide (BPDE) [46] and aflatoxin $\mathrm{B}_{1}-8,9$-epoxide [47]. In contrary, no inhibitory effect of $\mathrm{CHL}$ was observed against small, nonplanar alkylating agents, $\mathrm{N}^{\prime}$-methyl- $\mathrm{N}^{\prime}$ nitrosourea (MNU) and ethyl methanesulfonate (EMS) [46]. These findings strongly suggest that interception of aromatic mutagens in molecular complexes by CHL rather than modification of xenobiotic metabolizing enzymes accounts for the observed antimutagenic effects of CHL.

In vitro protective effects of CHL towards DNA were demonstrated in studies conducted by Pietrzak et al. [26]. Light absorption and fluorescence spectroscopy analyses of mutagen-CHL-DNA three-component mixtures revealed that CHL induced a dose-dependent decrease in the mutagen complexed with DNA concentration. Mutagens used in the study, acridine orange, quinacrine mustard, and doxorubicin, intercalate to DNA rather than form covalent adducts, which is typical of HCAs. Nevertheless, these in vitro findings support the hypothesis that direct interactions between aromatic mutagen and CHL molecules can influence its affinity to bind to DNA, irrespectively of any other complex mechanisms of action, which cannot be completely excluded when living organisms are used as experimental models.

\subsection{Adsorption of HCAs on Insoluble Carriers Containing} CHL. The "interceptor" mode of CHL chemopreventive action was further investigated in studies involving adsorption of aromatic mutagens on CHL bound to insoluble carriers, Sepharose [48] and chitosan [49]. It was demonstrated that a broad range of polycyclic planar mutagens, including non-IQ-type HCAs, Trp-P-1, and Trp-P-2, are strongly adsorbed on CHL covalently linked to Sepharose [48]. Additionally, the positive relationship between the strength of adsorption of particular mutagens on CHL-Sepharose and the efficacy of CHL in inhibiting their mutagenic activity was revealed [48]. The studies with CHL fixed on chitosan demonstrated that planar molecules having three or more fused rings (including IQ, MeIQ, MeIQx, Glu-P-1, and TrpP-2) efficiently adsorb on CHL-chitosan, whereas for tworing compounds tested, only those with significant planar surfaces, such as PhIP, noncovalently bind to CHL-chitosan [49]. Overall, the adsorption of aromatics to CHL-chitosan was much stronger than to CHL-Sepharose, and in contrast 
to CHL-Sepharose, mutagens adsorbed to CHL-chitosan are difficult to elute even at very low $\mathrm{pHs}$. The adsorption of HCAs on CHL-chitosan was proven to be relevant for in vivo protective effects of $\mathrm{CHL}$-chitosan coadministered with aromatic carcinogens. The amount of Trp-P-2-DNA adducts in liver and other organs was significantly decreased in a mice fed with Trp-P-2 and CHL-chitosan [50, 51], which was attributed to diminished absorption of CHL-chitosan bound mutagen from the gastrointestinal tract. CHL-chitosan was proven to be beneficial in humans, promoting the excretion of dioxins in feces and sebum [52].

3.4. CHL Influence on Carcinogen Bioavailability. Studies using Caco-2 monolayer transport model have shown that CHL reduces in vitro carcinogen uptake from the intestine [53]. In these studies, the influence of CHL on absorption rate of dibenzo[ $a, l]$ pyrene (DBP), AFB1, and PhIP through intestinal epithelial cells was monitored. CHL was shown to inhibit the transport of aromatic mutagens, being the most effective towards DBP, for which significant inhibition was observed for 1:10 ratio of mutagen:CHL. For AFB1, 1:100 ratio of mutagen: $\mathrm{CHL}$ was sufficient to reduce transport by almost 50\%, whereas 1:1000 ratio of mutagen : CHL was needed to inhibit PhIP absorption by $35 \%$. These differences in $\mathrm{CHL}$ efficiency to inhibit mutagen transport through Caco-2 monolayer can be explained by different affinities of CHL for analyzed mutagens, reflected by binding constants of mutagen-CHL interactions: the highest for BDP-CHL, intermediate for AFB1-CHL, and, according to Dashwood et al. [34], much lower for PhIP-CHL. These findings are concordant with the report of Dashwood and Guo [33], who suggested, basing on CHL-mutagen binding constants, that interceptor CHL action can be effective only when CHL concentrations are much higher than mutagen concentrations, for example, IQ: CHL weight ratio of $1: 27000$ ensures complete sequestration of IQ in complexes with CHL. Nevertheless, taking into consideration relatively high $\mathrm{CHL}$ doses and low dietary exposure to most carcinogens, it seems possible that high CHL: carcinogen ratio could be easily achieved in the gastrointestinal tract. Hence, CHL might act as a first line of defense, forming noncovalent heterocomplexes with aromatic food-borne mutagens/carcinogens and lowering their absorption from the gastrointestinal tract. Earlier in vivo studies with rat intestinal loop absorption model gave similar results; CHL administration to isolated intestinal loops diminished the bioavailability and absorption of IQ [28].

3.5. Animal Studies on CHL Protection towards HCAs and Other Dietary Carcinogens. The antigenotoxic potential of CHL against HCAs was observed in numerous studies with laboratory animals. Cotreatment of F344 rats with PhIP and CHL reduced mammary gland cancer incidences [54]. Similar protection against PhIP-induced mammary carcinogenesis in F344 rats by CHL was observed by Hirose et al. [55]. Studies on the CHL's influence on the carcinogenic activity of IQ in rats revealed that CHL protected against colon, liver, and small intestine cancers [56]. Furthermore,
CHL was proven to protect against PhIP-induced aberrant crypt foci (ACF) in F344 rats, decreasing the uptake of a mutagen from the gastrointestinal tract, as concluded from augmented elimination of unmetabolized PhIP in feces in the presence of CHL [57]. CHL inhibited IQ-induced DNA adduct formation in rat liver by interacting with mutagen directly and thus reducing its uptake from the intestine [28]. In addition, it was demonstrated that cotreatment of rats with IQ and CHL resulted in increased urinary and fecal excretion of unmetabolized mutagen, confirming that CHL can act as interceptor molecule, interacting with planar mutagens and decreasing their bioavailability in the gastrointestinal tract and tissues [58]. Studies on Drosophila larvae revealed that CHL significantly inhibited MeIQx-DNA adduct formation. It was concluded that large doses of $\mathrm{CHL}$ can interact with and effectively intercept MeIQx in feed as well as in the gastrointestinal tract of larvae, inhibiting its bioavailability and absorption [59]. Similar CHL protective effects were also observed towards other aromatic mutagens. Chlorophyll inhibited absorption of dioxins from the gastrointestinal tract [60]. Direct interactions between chlorophyll, CHL and, dibenzo $[a, l]$ pyrene (DBP) contributed to the reduced uptake of the mutagen to the liver, thus diminishing stomach and liver cancer incidents in rainbow trout [61]. Chemopreventive properties of natural chlorophyll and CHL were also described for another aromatic mutagen/carcinogenAFB1, and AFB1-induced carcinogenesis in rats [62]. The protection resulted from decreased mutagen uptake from the intestines, which was concluded from the increased excretion of AFB1 in feces of CHL- and chlorophyll-fed animals. Moreover, molecular complexes formation between two anticarcinogens and AFB1 were confirmed by fluorescence quenching experiments, with 1:1 stoichiometries and dissociation constants $K_{d}=1.22 \mu \mathrm{M}$ and $3.05 \mu \mathrm{M}$ for AFB1chlorophyll and AFB1-CHL interactions, respectively [62]. CHL administered together with AFB1 in the diet inhibited AFB1-DNA binding in trout. Interestingly, lower protective effects were observed when AFB1 was given to animals by intraperitoneal injection, thus significantly reducing the possibility of direct interactions between CHL and mutagen in the intestines [47]. Similar observations were made by Guo and Dashwood [63]. They demonstrated that simultaneous administration of IQ and CHL to rats is crucial to exert the most effective inhibition of IQ-DNA binding. These findings serve as additional evidence for interceptor mode of $\mathrm{CHL}$ protective action.

3.6. Chemoprotective Effects of CHL in Human Studies. $\mathrm{CHL}$ was proven to act as HCAs protective agent in human studies. It was demonstrated that CHL tablets administered to humans exert inhibitory effects against DNA damage induced by HCA-containing fried meat in target colorectal cells [64]. Clinical chemoprevention trial on a human population with high AFB1 exposure revealed that $100 \mathrm{mg}$ of dietary CHL three times per day significantly reduces the level of aflatoxin$\mathrm{N}^{7}$-guanine, hepatic DNA adduct biomarker in urine [65]. This study clearly demonstrated that CHL can be an effective agent suitable for use in reducing human cancer risk from 
dietary AFB1. Detailed pharmacokinetics studies on human volunteers treated with microdoses ( $30 \mathrm{ng}$ ) of AFB1 indicated that chlorophyll as well as CHL administration significantly influenced various pharmacokinetic parameters and reduced systemic AFB1 absorption [66]. These findings directly suggest that CHL and chlorophyll exert protective effects in humans by decreasing aromatic mutagens bioavailability.

\section{Role of Caffeine and Other Methylxanthines}

Caffeine (CAF), a component of several popular beverages (coffee, tea, and energy drinks), is the most widely consumed alkaloid worldwide. Statistical data from the USA revealed that the average daily intake of CAF can reach $193 \mathrm{mg} /$ day per person [67]. Many epidemiological studies suggest that caffeine can reduce the risk of cancer [68-71]. Since the influence of caffeine on human body is exceedingly complex, its overall mechanism of action as a chemopreventive agent is still not fully understood. It is commonly known that CAF can modulate the metabolism of xenobiotics, mainly by the induction of cytochrome P450 enzymes. Therefore, it is believed that CAF may exert its protective action through the enhancement of detoxication pathways of numerous carcinogenic compounds. On the other hand, CAF is intensively metabolized through cytochrome $\mathrm{P} 450$ isoenzyme 1A2 (CYP1A2) [72]. Thus, competitive inhibition of CYP1A2 can be mentioned as one of the possible mechanisms of CAF protective action towards several procarcinogens, for example, HCAs, which are biologically activated by CYP1A2.

4.1. Inhibition of HCAs Activity by CAF. It was demonstrated that caffeine-rich beverages, such as different types of tea [7376] as well as coffee [77], can inhibit HCAs biological activity. Moreover, decaffeinated tea was shown to be less effective in reducing PhIP mutagenic activity than regular tea [75].

CAF was proven to attenuate mutagenic effects of MeIQ, Trp-P-2, MeIQx [78, 79], and PhIP [75]. This protective CAF potential was attributed to the inhibition of microsomal enzymes (e.g., CYP1A2) involved in HCAs bioactivation. Experiments with laboratory animals revealed that administration of CAF-containing beverages not only protected against IQ-induced genotoxicity, but also caused about 20$30 \%$ induction of CYP1A2 and CYP1A1 isoenzymes [76]. The latter should augment rather than diminish HCAs genotoxicity by increased HCAs bioactivation ratio to highly reactive arylnitrenium intermediates, suggesting that mechanisms other than the modulation of phase I enzymes can be involved in observed protective action. The inhibitory effects of tea extracts towards promutagens (IQ, Glu-P-1) as well as directacting mutagens (9-aminoacridine and N-methyl-N-nitro$\mathrm{N}$-nitrosoguanidine) further support the hypothesis that protective effects of CAF cannot be fully explained by its influence on xenobiotic activation system [80]. The presence of mechanisms additional to the inhibition of cytochrome P450 enzymatic activity was also suggested by Chen and Yen [73]. Furthermore, Weisburger et al. specified alternative mechanisms of CAF action against HCAs, among which the possibility of direct interactions between planar CAF and HCAs molecules was proposed [75].

4.2. Molecular Complexes Formation between HCAs, CAF, and Other Methylxanthines. The idea of heterocomplexation between CAF and HCAs was further investigated for IQtype HCAs and CAF as well as other methylxanthines (MTX), pentoxifylline (PTX), and theophylline (TH) [15]. In order to examine direct interactions between IQ-type HCAs and MTX, light absorption spectra of mutagens titrated with MTX were measured and analyzed for each HCA-MTX pair. Distinctive spectral changes, bathochromic and hypochromic shift, were observed, indicating stacking $(\pi-\pi)$ complexes formation between analyzed compounds. Provided CAF and other MTX form homoaggregates in aqueous solution, the determination of association constant for mutagen-MTX interaction $K_{b}$ from Benesi-Hildebrand plot is not a very accurate approach. MTX homocomplexation can be significant especially for high (milimolar range) MTX concentrations, hence free/bound MTX ratio cannot be directly related to the amount of added mutagen. Therefore, statistical-thermodynamical model of mixed aggregation [81] which assumes infinite self-aggregation of one of the interacting ligands was applied in this study in order to calculate neighborhood association constants $K_{\mathrm{AC}}$ of HCAMTX interactions. The obtained $K_{\mathrm{AC}}$ values of HCA-MTX interactions were within $10^{2} \mathrm{M}^{-1}$ range. Moreover, the model was used to estimate the concentrations of each possible component of every analyzed HCA-MTX mixture (i.e., concentration of MTX monomers and MTX homoaggregates and concentration of HCA monomers and HCA-MTX complexes). It was demonstrated that $100: 1$ ratio of MTX: HCA was enough to sequester more than $80 \%$ mutagen molecules in complexes with MTX [15]. Thus, CAF and other MTX seem to be much more effective in intercepting HCAs than CHL, for which $27000: 1 \mathrm{CHL}$ : mutagen ratio was proposed for efficient HCA binding [33]. IQ-MTX binding efficiency determined in vitro was confirmed in mutagenicity studies [15]. Ames test experiments revealed that CAF, PTX, and TH caused a significant dose-dependent reduction of IQ mutagenic activity. A strong linear correlation between mutagenic activity of IQ-MTX mixtures and free form of IQ suggests that CAF and other MTX antimutagenic activities can be explained by sequestration of HCAs molecules in heterocomplexes with MTX. Moreover, these findings indicate that thermodynamical models can be a useful tool to estimate the biological effects of biologically-active aromatic compounds heterocomplexation and to predict to what extent interceptor potential may contribute to overall protective action of several aromatic compounds.

Hernaez et al. reported that CAF forms molecular complexes with direct-acting IQ derivative $\mathrm{N}$-OH-IQ, with association constant $K_{b}<0.5 \cdot 10^{3} \mathrm{M}^{-1}$, determined by spectrophotometric titration experiments and Benesi-Hildebrand plot [45]. However, in contrast to the above-mentioned studies [15], no protective effect of CAF against mutagenic activity of $\mathrm{N}-\mathrm{OH}$-IQ was observed up to $250 \mathrm{nmole}$ CAF per plate. 
4.3. Heterocomplexation of MTX with Other Aromatic Ligands. Although there are only few reports describing studies on interception role of CAF and other MTX towards HCAs, heterocomplexation of MTX with other aromatic compounds has been broadly investigated. It has been reported previously that CAF and other MTX form stacking aggregates with aromatic dyes: acridine orange [82-84], ethidium bromide $[20,81,85], 4^{\prime}$,6-diamidino-2-phenylindole (DAPI) [81], methylene blue [86], anticancer drugs: doxorubicin, mitoxantrone, and daunomycin $[17,24,81,87]$, antibacterial agent norfloxacin [88], vitamin $\mathrm{B}_{2}$ derivative flavinmononucleotide [87], neurotoxins [36, 89], and aromatic mutagens $[22,35]$. Some of these reports reveal in vivo effects of observed heterocomplexation, indicating that molecular complex formation between aromatic compounds can be relevant in biological systems [22, 35, 36, 89].

It was demonstrated that CAF and other MTX can inhibit DNA binding or even induce deintercalation of aromatic ligands from DNA $[20,21,84,88]$. It is still discussed whether this effect results barely from the decrease in ligand availability due to its interception by MTX or can be also contributed to the reduction of binding sites on DNA available for ligands caused by MTX intercalation. Nevertheless, these findings clearly demonstrate that direct interactions between aromatic compounds can significantly modify their biological properties.

\section{Other BACs}

5.1. Role of Polyphenols. Polyphenols are naturally occurring, aromatic compounds containing at least two phenolic rings. They are extensively studied for their antimicrobial, anticarcinogenic, and antiinflammatory properties [90]. In the field of chemoprevention, they show potential to both scavenge reactive oxygen species and form heterocomplexes with aromatic mutagens [91, 92]. The latter mechanism, as described before, reduces mutagenic potential of aromatic mutagens by formation of molecular complexes with aromatic mutagens, thus reducing their bioavailability. Such effects were described for one of the model mutagens, acridine orange, and resveratrol by Osowski et al. [27].

Numerous studies concerning chemopreventive mechanisms of polyphenolic compounds against heterocyclic aromatic amines were conducted. Research carried out by Hernaez et al. reveals that $\mathrm{N}$-OH-IQ (direct-acting IQ derivative) binds to (-)-epigallocatechin gallate (EGCG), (-)epigallocatechin (EGC), (+)-catechin, and (-)-epicatechin gallate (ECG) directly. The binding constants determined from Benesi-Hildebrand plot for these polyphenolic compounds are in the range of $1 \cdot 10^{3} \mathrm{M}^{-1}$ [45]. Nevertheless, authors of this work suggest that determined interaction constants are too low to contribute to observed inhibition of HCAs mutagenic activity [45]. However, two works of Dashwood and Guo demonstrate IQ-CHL interaction constant determined from Benesi-Hildebrand plot in the range of $7 \cdot 10^{3} \mathrm{M}^{-1}$. Nonetheless, authors consider the interactions probable and important CHL chemopreventive mechanism, especially for high CHL:IQ ratios (the ratio of CHL:IQ required to bind $99.9 \%$ is greater than $27000: 1)$ [29, 33]. Results for IQ-MTX interactions published by Woziwodzka et al. demonstrate that MTX reduce mutagenic activity of HCAs despite mixed association constants in the range of $1 \cdot 10^{2} \mathrm{M}^{-1}$ [15]. Considering these data, it can be speculated that binding constants in the range of $1 \cdot 10^{3} \mathrm{M}^{-1}$ indicate the mechanism of HCAs sequestration by polyphenolic compounds as plausible and suggest its role in chemopreventive action of these compounds against HCAs apart from activation of phase II enzymes and free radicals scavenging.

Additionally, Artemisia argyi analysis performed by Nakasugi et al. revealed that flavones reduce mutagenic activity of Trp-P-2 [93]. Comparison of Ames mutagenicity test results for Trp-P-2 and its active form, Trp-P-2[NHOH], indicate that, apart from other mechanisms, also heterocomplexes formation should be considered as important chemopreventive mechanism of different flavones, namely eupatilin, jaceosidin, apigenin, and chrysoeriol. Presented results demonstrate that mechanism of heterocomplexes formation is responsible for up to $30 \%$ of overall reduction of HCAs mutagenic activity in the Ames test. Moreover, presented data demonstrate Trp-P-2 fluorescence quenching in a dose-dependent manner by mentioned flavones, indicating heterocomplexes formation between Trp-P-2 and flavones [93].

Furthermore, Arimoto-Kobayashi et al. findings suggest that polyphenolic compounds present in beer can act as HCAs interceptors [94]. Beer and other phenol-containing beverages (i.e., red and white wine, sake, and brandy) exhibited strong antimutagenic effects against Trp-P-2 and Trp-P-2[NHOH] in the Ames test. The protective effect of beer polyphenols was observed only when mutagen was administered simultaneously with beer. Neither pre- nor posttreatment with beer caused any protective effects towards bacteria in the Ames test [94]. In contrast, bacteria pretreatment with wine polyphenolic compounds (e.g., ellagic acid) resulted in decrease in Trp-P-2[NHOH] mutagenic activity, probably due to their antioxidative properties [95].

5.2. Role of Plant Dyes. Plant dyes of aromatic structure that cannot be classified as porphyrins or phenolic compounds also show promising chemopreventive activity. Izawa et al. analyzed Monacus dyes chemopreventive action against direct-acting Trp-P-2 derivative, Trp-P-2[NHOH] [96]. Their findings suggest that aromatic dyes present in Monacus plants, especially red and yellow dye, significantly reduce HCAs mutagenic activity, with observed inhibitory effect for red and yellow dyes reaching $55 \%$. What is important is that spectrophotometric study of Trp-P-2[NHOH] interactions with yellow dye showed significant spectral changes suggesting strong interactions between dye and mutagen. Moreover, the authors suggested that dye-HCA heterocomplexes formation can induce observed degradation of Trp-P-2[NHOH] [96]. These results indicate that, apart from chlorophyllin, other natural dyes can be also involved in protection towards HCAs by reduction of mutagen bioavailability and enhancing its degradation through heterocomplexes formation. 
5.3. Role of Dietary Fiber. Several reports describe binding of HCAs, including MeIQx, Trp-P-1, Trp-P-2, and Glu$\mathrm{P}-1$, to the dietary fibers [77, 97]. Formation of MeIQxfiber complexes reduces mutagen uptake in rats, increasing excreted amount of mutagen and reducing time of HCAs transition through gastrointestinal tract $[98,99]$. The affinity of such binding is dependent on both fiber and MeIQx concentrations $[97,100]$ with both environment $\mathrm{pH}$ and compounds hydrophobicity being other factors to consider $[100,101]$. Additionally, Ryden and Robertson observed no influence of bile salts on MeIQx binding to fiber. This remark allowed the authors to suggest that planar structure of molecule is required to bind to the fiber [100]. These findings indicate fiber potential to form heterocomplexes with aromatic mutagens and its possible role in chemoprevention.

\section{Conclusions}

According to the World Health Organization, cancer is responsible for as much as $13 \%$ of all deaths, being second most frequent cause of death worldwide. The number of cancer incidents increases every year, and it is expected to exceed 11 million in 2030. It is estimated that up to $40 \%$ of all cancer deaths result from the exposure to behavioral and environmental risk factors. Diet, accounting for even $30 \%$ of cancers in industrialized countries, is one of the risk factors which can be easily modified. Thus, the research on the role of diet in cancer appears to be a matter of great interest. There are many food constituents with carcinogenic or anticarcinogenic potential. Among carcinogens, great attention is paid to HCAs, present in thermal processed meat. On the other hand, it was demonstrated that consumption of several BACs can protect against several types of cancer. Since the influence of BACs on human body can be very diverse, their possible mechanisms of chemoprevention are still discussed. One of the possible explanations of BACs protective action is their direct noncovalent interactions with HCAs, which may lead to the sequestration of mutagens, blocking their bioavailability and thus reducing their genotoxic potential. Even though numerous works describing action of dietary BACs are published, there is still a lot to be done to evaluate the mechanism of such compounds action and their role in cancer prevention.

\section{Acknowledgment}

One of the authors (A. Woziwodzka) was financed from European Social Fund as a part of the project "Educators for the elite-integrated training program for $\mathrm{PhD}$ students, post-docs and professors as academic teachers at the University of Gdansk" within the framework of Human Capital Operational Programme, Action 4.1.1, improving the quality of educational offer of tertiary education institutions.

\section{References}

[1] E. M. P. Widmark, "Presence of cancer-producing substances in roasted food," Nature, vol. 143, no. 3632, p. 984, 1939.
[2] M. Nagao, M. Honda, Y. Seino, T. Yahagi, and T. Sugimura, "Mutagenicities of smoke condensates and the charred surface of fish and meat," Cancer Letters, vol. 2, no. 4-5, pp. 221-226, 1977.

[3] K. Wakabayashi, M. Nagao, H. Esumi, and T. Sugimura, "Foodderived mutagens and carcinogens," Cancer Research, vol. 52, no. 7, pp. 2092s-2098s, 1992.

[4] H. Kataoka, "Methods for the determination of mutagenic heterocyclic amines and their applications in environmental analysis," Journal of Chromatography A, vol. 774, no. 1-2, pp. 121142, 1997.

[5] T. Sugimura, K. Wakabayashi, H. Nakagama, and M. Nagao, "Heterocyclic amines: mutagens/carcinogens produced during cooking of meet and fish," Cancer Science, vol. 95, no. 4, pp. 290299, 2004.

[6] Q. Dai, X. O. Shu, F. Jin, Y. T. Gao, Z. X. Ruan, and W. Zheng, "Consumption of animal foods, cooking methods, and risk of breast cancer," Cancer Epidemiology Biomarkers and Prevention, vol. 11, no. 9, pp. 801-808, 2002.

[7] M. Gerhardsson De Verdier, U. Hagman, R. K. Peters, G. Steineck, and E. Overvik, "Meat, cooking methods and colorectal cancer: a case-referent study in Stockholm," International Journal of Cancer, vol. 49, no. 4, pp. 520-525, 1991.

[8] S. E. Norell, A. Ahlbom, R. Erwald et al., "Diet and pancreatic cancer: a case-control study," American Journal of Epidemiology, vol. 124, no. 6, pp. 894-902, 1986.

[9] G. Steineck, U. Hagman, M. Gerhardsson, and S. E. Norell, "Vitamin a supplements, fried foods, fat and urothelial cancer. A case-referent study in Stockholm in 1985-87," International Journal of Cancer, vol. 45, no. 6, pp. 1006-1011, 1990.

[10] E. G. Snyderwine, H. A. J. Schut, R. H. Adamson, U. P. Thorgeirsson, and S. S. Thorgeirsson, "Metabolic activation and genotoxicity of heterocyclic arylamines," Cancer Research, vol. 52, no. 7, pp. 2099-2102, 1992.

[11] IARC, Some Naturally Occurring and Synthetic Food Components, Furocoumarins and Ultraviolet Radiation., vol. 40 of IARC Monographs on the Evaluation of Carcinogenic Risks to Humans, IARC, Lyon, France, 1986.

[12] IARC, Some Naturally Occuring Substances: Food Items and Constituents, Heterocyclic Aromatic Amines and Mycotoxins, vol. 56 of IARC Monographs on the Evaluation of Carcinogenic Risks to Humans, IARC, Lyon, France, 1993.

[13] C. E. Schwab, W. W. Huber, W. Parzefall et al., "Search for compounds that inhibit the genotoxic and carcinogenic effects of heterocyclic aromatic amines," Critical Reviews in Toxicology, vol. 30, no. 1, pp. 1-69, 2000.

[14] R. H. Dashwood, "Modulation of heterocyclic amine-induced mutagenicity and carcinogenicity: an "A-to-Z" guide to chemopreventive agents, promoters, and transgenic models," Mutation Research, vol. 511, no. 2, pp. 89-112, 2002.

[15] A. Woziwodzka, A. Gwizdek-Wiśniewska, and J. Piosik, "Caffeine, pentoxifylline and theophylline form stacking complexes with IQ-type heterocyclic aromatic amines," Bioorganic Chemistry, vol. 39, no. 1, pp. 10-17, 2011.

[16] D. D. Andrejuk, A. A. Hernandez Santiago, V. V. Khomich, V. K. Voronov, D. B. Davies, and M. P. Evstigneev, "Structural and thermodynamic analysis of the hetero-association of theophylline with aromatic drug molecules," Journal of Molecular Structure, vol. 889, no. 1-3, pp. 229-236, 2008.

[17] J. Piosik, M. Zdunek, and J. Kapuscinski, “The modulation by xanthines of the DNA-damaging effect of polycyclic aromatic 
agents: part II. The stacking complexes of caffeine with doxorubicin and mitoxantrone," Biochemical Pharmacology, vol. 63, no. 4, pp. 635-646, 2002.

[18] M. A. Semenov, I. Blyzniuk, T. V. Bolbukh, A. V. Shestopalova, M. P. Evstigneev, and V. Y. Maleev, "Intermolecular hydrogen bonds in hetero-complexes of biologically active aromatic molecules probed by the methods of vibrational spectroscopy," Spectrochimica Acta A, vol. 95, pp. 224-229, 2012.

[19] E. Bedner, L. Du, F. Traganos, and Z. Darzynkiewicz, "Caffeine dissociates complexes between DNA and intercalating dyes: application for bleaching fluorochrome-stained cells for their subsequent restaining and analysis by laser scanning cytometry," Cytometry, vol. 43, no. 1, pp. 38-45, 2001.

[20] J. Piosik, K. Wasielewski, A. Woziwodzka, W. Śledź, and A. Gwizdek-Wiśniewska, "De-intercalation of ethidium bromide and propidium iodine from DNA in the presence of caffeine," Central European Journal of Biology, vol. 5, no. 1, pp. 59-66, 2010.

[21] S. F. Baranovsky, P. A. Bolotin, M. P. Evstigneev, and D. N. Chernyshev, "Interaction of ethidium bromide and caffeine with DNA in aqueous solution," Journal of Applied Spectroscopy, vol. 76, no. 1, pp. 132-139, 2009.

[22] J. Piosik, K. Ulanowska, A. Gwizdek-Wiśniewska, A. Czyz, J. Kapuściński, and G. Wȩgrzyn, "Alleviation of mutagenic effects of polycyclic aromatic agents (quinacrine mustard, ICR-191 and ICR-170) by caffeine and pentoxifylline," Mutation Research, vol. 530, no. 1-2, pp. 47-57, 2003.

[23] A. S. Buchelnikov, A. A. Hernandez Santiago, F. M. Gonzalez, R. R. Vazquez, D. B. Davies, and M. P. Evstigneev, "General analysis of competitive binding in drug-interceptor-DNA systems," European Biophysics Journal, vol. 41, no. 3, pp. 273-283, 2012.

[24] J. Piosik, A. Gwizdek-Wisniewska, K. Ulanowska, J. Ochocinski, A. Czyz, and G. Wegrzyn, "Methylxanthines (caffeine, pentoxifylline and theophylline) decrease the mutagenic effect of daunomycin, doxorubicin and mitoxantrone," Acta Biochimica Polonica, vol. 52, no. 4, pp. 923-926, 2005.

[25] G. M. Hill, D. M. Moriarity, and W. N. Setzer, "Attenuation of cytotoxic natural product DNA intercalating agents by caffeine," Scientia Pharmaceutica, vol. 79, pp. 729-747, 2011.

[26] M. Pietrzak, Z. Wieczorek, J. Wieczorek, and Z. Darzynkiewicz, "The "interceptor" properties of chlorophyllin measured within the three-component system: intercalator-DNA-chlorophyllin," Biophysical Chemistry, vol. 123, no. 1, pp. 11-19, 2006.

[27] A. Osowski, M. Pietrzak, Z. Wieczorek, and J. Wieczorek, "Natural compounds in the human diet and their ability to bind mutagens prevents DNA-mutagen intercalation," Journal of Toxicology and Environmental Health A, vol. 73, no. 17-18, pp. 1141-1149, 2010.

[28] R. H. Dashwood, "Protection by chlorophyllin against the covalent binding of 2-amino-3-methylimidazo[4,5-f] quinoline (IQ) to rat liver DNA," Carcinogenesis, vol. 13, no. 1, pp. 113-118, 1992.

[29] R. Dashwood and D. Guo, "Antimutagenic potency of chlorophyllin in the Salmonella assay and its correlation with binding constants of mutagen-inhibitor complexes," Environmental and Molecular Mutagenesis, vol. 22, no. 3, pp. 164-171, 1993.

[30] H. A. J. Schut and E. G. Snyderwine, "DNA adducts of heterocyclic amine food mutagens: implications for mutagenesis and carcinogenesis," Carcinogenesis, vol. 20, no. 3, pp. 353-368, 1999.

[31] R. J. Turesky and P. Vouros, "Formation and analysis of heterocyclic aromatic amine-DNA adducts in vitro and in vivo," Journal of Chromatography B, vol. 802, no. 1, pp. 155-166, 2004.
[32] M. D. Waters, H. F. Stack, M. A. Jackson, H. E. Brockman, and S. De Flora, "Activity profiles of antimutagens: in vitro and in vivo data," Mutation Research, vol. 350, no. 1, pp. 109-129, 1996.

[33] R. Dashwood and D. Guo, "Inhibition of 2-amino-3-methylimidazo[4,5-f] quinoline (IQ)-DNA binding by chlorophyllin: studies of enzyme inhibition and molecular complex formation," Carcinogenesis, vol. 13, no. 7, pp. 1121-1126, 1992.

[34] R. Dashwood, S. Yamane, and R. Larsen, "Study of the forces of stabilizing complexes between chlorophylls and heterocyclic amine mutagens," Environmental and Molecular Mutagenesis, vol. 27, no. 3, pp. 211-218, 1996.

[35] J. Kapuscinski, B. Ardelt, J. Piosik, M. Zdunek, and Z. Darzynkiewicz, "The modulation of the DNA-damaging effect of polycyclic aromatic agents by xanthines: part I. Reduction of cytostatic effects of quinacrine mustard by caffeine," Biochemical Pharmacology, vol. 63, no. 4, pp. 625-634, 2002.

[36] K. Ulanowska, J. Piosik, A. Gwizdek-Wiśniewska, and G. Wegrzyn, "Impaired mutagenic activities of MPDP+ (1methyl-4-phenyl-2,3-dihydropyridinium) and $\mathrm{MPP}+$ (1methyl-4-phenylpyridinium) due to their interactions with methylxanthines," Bioorganic and Medicinal Chemistry, vol. 15, no. 15, pp. 5150-5157, 2007.

[37] C. H. Yun, H. G. Jeong, J. W. Jhoun, and F. P. Guengerich, "Nonspecific inhibition of cytochrome P450 activities by chlorophyllin in human and rat liver microsomes," Carcinogenesis, vol. 16, no. 6, pp. 1437-1440, 1995.

[38] N. Tachino, D. Guo, W. M. Dashwood, S. Yamane, R. Larsen, and R. Dashwood, "Mechanisms of the in vitro antimutagenic action of chlorophyllin against benzo[a]pyrene: studies of enzyme inhibition, molecular complex formation and degradation of the ultimate carcinogen," Mutation Research, vol. 308, no. 2, pp. 191-203, 1994.

[39] G. C. Bez, B. Q. Jordão, V. E. P. Vicentini, and M. S. Mantovani, "Investigation of genotoxic and antigenotoxic activities of chlorophylls and chlorophyllin in cultured V79 cells," Mutation Research, vol. 497, no. 1-2, pp. 139-145, 2001.

[40] O. Olvera, C. Arceo, and S. Zimmering, "Chlorophyllin [CHLN] and the mutagenicity of monofunctional alkylating agents in Drosophila: the action of CHLN need not include an influence on metabolic activation," Mutation Research, vol. 467, no. 2, pp. 113-117, 2000.

[41] S. S. Kumar, R. C. Chaubey, T. P. A. Devasagayam, K. I. Priyadarsini, and P. S. Chauhan, "Inhibition of radiationinduced DNA damage in plasmid pBR322 by chlorophyllin and possible mechanism(s) of action," Mutation Research, vol. 425, no. 1, pp. 71-79, 1999.

[42] S. S. Kumar, B. Shankar, and K. B. Sainis, "Effect of chlorophyllin against oxidative stress in splenic lymphocytes in vitro and in vivo," Biochimica et Biophysica Acta, vol. 1672, no. 2, pp. 100-111, 2004.

[43] Y. K. Bae, A. Brown, E. Garrett et al., "Hypermethylation in histologically distinct classes of breast cancer," Clinical Cancer Research, vol. 10, no. 18, pp. 5998-6005, 2004.

[44] T. Negishi, S. Arimoto, C. Nishizaki, and H. Hayatsu, "Inhibitory effect of chlorophyll on the genotoxicity of 3-amino1-methyl-5H-pyrido[4,3-b]indole (Trp-P-2)," Carcinogenesis, vol. 10, no. 1, pp. 145-149, 1989.

[45] J. Hernaez, M. Xu, and R. Dashwood, "Effects of tea and chlorophyllin on the mutagenicity of N-hydroxy-IQ: studies of enzyme inhibition, molecular complex formation, and degradation/scavenging of the active metabolites," Environmental and Molecular Mutagenesis, vol. 30, no. 4, pp. 468-474, 1997. 
[46] L. Romert, M. Curvall, and D. Jenssen, "Chlorophyllin is both a positive and negative modifier of mutagenicity," Mutagenesis, vol. 7, no. 5, pp. 349-355, 1992.

[47] R. H. Dashwood, V. Breinholt, and G. S. Bailey, "Chemopreventive properties of chlorophyllin: inhibition of aflatoxin B1 (AFB1)-DNA binding in vivo and anti-mutagenic activity against AFB1 and two heterocyclic amines in the Salmonella mutagenicity assay," Carcinogenesis, vol. 12, no. 5, pp. 939-942, 1991.

[48] S. Arimoto, S. Fukuoka, C. Itome, H. Nakano, H. Rai, and H. Hayatsu, "Binding of polycyclic planar mutagenesis to chlorophyllin resulting in inhibition of the activity," Mutation Research, vol. 287, no. 2, pp. 293-305, 1993.

[49] S. Arimoto-Kobayashi, N. Harada, R. Tokunaga, J. I. Odo, and H. Hayatsu, "Adsorption of mutagens to chlorophyllin-chitosan, an insoluble form of chlorophyllin," Mutation Research, vol. 381, no. 2, pp. 243-249, 1997.

[50] N. Anzai, T. Taniyama, N. Nakandakari et al., "Inhibition of DNA adduct formation and mutagenic action of 3-amino1-methyl-5H-pyrido[4,3-b]indole by chlorophyllin-chitosan in rpsL transgenic mice," Japanese Journal of Cancer Research, vol. 92, no. 8, pp. 848-853, 2001.

[51] C. Sugiyama, N. Nakandakari, H. Hayatsu, and S. ArimotoKobayashi, "Preventive effects of chlorophyllin fixed on chitosan towards DNA adduct formation of 3-amino-1-methyl5H-pyrido[4,3-b]indole in CDF1 mice," Biological and Pharmaceutical Bulletin, vol. 25, no. 4, pp. 520-522, 2002.

[52] K. Kitamura, M. Nagao, H. Hayatsu, and M. Morita, "Effect of chlorophyllin-chitosan on excretion of dioxins in a healthy man," Environmental Science and Technology, vol. 39, no. 4, pp. 1084-1091, 2005.

[53] J. E. Mata, Z. Yu, J. E. Gray, D. E. Williams, and R. Rodriguez-Proteau, "Effects of chlorophyllin on transport of dibenzo(a,l)pyrene, 2-amino-1-methyl-6-phenylimidazo-[4,5b]pyridine, and aflatoxin B1 across Caco-2 cell monolayers," Toxicology, vol. 196, no. 1-2, pp. 117-125, 2004.

[54] R. Hasegawa, M. Hirose, T. Kato et al., "Inhibitory effect of chlorophyllin on PhIP-induced mammary carcinogenesis in female F344 rats," Carcinogenesis, vol. 16, no. 9, pp. 2243-2246, 1995.

[55] M. Hirose, A. Nishikawa, M. Shibutani, T. Imai, and T. Shirai, "Chemoprevention of heterocyclic amine-induced mammary carcinogenesis in rats," Environmental and Molecular Mutagenesis, vol. 39, no. 2-3, pp. 271-278, 2002.

[56] D. Guo, D. T. Horio, J. S. Grove, and R. H. Dashwood, "Inhibition by chlorophyllin of 2-amino-3-methylimidazo[4,5f] quinoline-induced tumorigenesis in the male F344 rat," Cancer Letters, vol. 95, no. 1-2, pp. 161-165, 1995.

[57] D. Guo, H. A. J. Schut, C. D. Davis, E. G. Snyderwine, G. S. Bailey, and R. H. Dashwood, "Protection by chlorophyllin and indole-3-carbinol against 2-amino-1-methyl-6phenylimidazo[4,5-b]pyridine (PhIP)-induced DNA adducts and colonic aberrant crypts in the F344 rat," Carcinogenesis, vol. 16, no. 12, pp. 2931-2937, 1995.

[58] R. Dashwood and C. Liew, "Chlorophyllin-enhanced excretion of urinary and fecal mutagens in rats given 2-amino-3methylimidazo[4,5-f]quinoline," Environmental and Molecular Mutagenesis, vol. 20, no. 3, pp. 199-205, 1992.

[59] C. Sugiyama, A. Shinoda, H. Hayatsu, and T. Negishi, "Inhibition of 2-Amino-3,8-dimethylimidazo[4,5-f] quinoxaline-mediated DNA-adduct formation by chlorophyllin in
Drosophila," Japanese Journal of Cancer Research, vol. 87, no. 4, pp. 325-328, 1996.

[60] K. Morita, M. Ogata, and T. Hasegawa, "Chlorophyll derived from Chlorella inhibits dioxin adsorption from the gastrointestinal tract and accelerates dioxin excretion in rats," Environmental Health Perspectives, vol. 109, no. 3, pp. 289-294, 2001.

[61] M. T. Simonich, T. McQuistan, C. Jubert et al., "Low-dose dietary chlorophyll inhibits multi-organ carcinogenesis in the rainbow trout," Food and Chemical Toxicology, vol. 46, no. 3, pp. 1014-1024, 2008.

[62] M. T. Simonich, P. A. Egner, B. D. Roebuck et al., "Natural chlorophyll inhibits aflatoxin B1-induced multi-organ carcinogenesis in the rat," Carcinogenesis, vol. 28, no. 6, pp. 1294-1302, 2007.

[63] D. Guo and R. Dashwood, "Inhibition of 2-amino-3-methylimidazo[4,5-f] quinoline (IQ)-DNA binding in rats given chlorophyllin: dose-response and time-course studies in the liver and colon," Carcinogenesis, vol. 15, no. 4, pp. 763-766, 1994.

[64] D. T. Shaughnessy, L. M. Gangarosa, B. Schliebe et al., "Inhibition of fried meat-induced colorectal dna damage and altered systemic genotoxicity in humans by crucifera, chlorophyllin, and yogurt," PLoS ONE, vol. 6, no. 4, Article ID e18707, 2011.

[65] P. A. Egner, A. Muñoz, and T. W. Kensler, "Chemoprevention with chlorophyllin in individuals exposed to dietary aflatoxin," Mutation Research, vol. 523-524, pp. 209-216, 2003.

[66] C. Jubert, J. Mata, G. Bench et al., "Effects of chlorophyll and chlorophyllin on low-dose aflatoxin B 1 pharmacokinetics in human volunteers," Cancer Prevention Research, vol. 2, no. 12, pp. 1015-1022, 2009.

[67] C. D. Frary, R. K. Johnson, and M. Q. Wang, "Food sources and intakes of caffeine in the diets of persons in the United States," Journal of the American Dietetic Association, vol. 105, no. 1, pp. 110-113, 2005.

[68] D. Ganmaa, W. C. Willett, T. Y. Li et al., "Coffee, tea, caffeine and risk of breast cancer: a 22-year follow-up," International Journal of Cancer, vol. 122, no. 9, pp. 2071-2076, 2008.

[69] A. Nkondjock, "Coffee consumption and the risk of cancer: an overview," Cancer Letters, vol. 277, no. 2, pp. 121-125, 2009.

[70] L. Rosenberg, "Coffee and tea consumption in relation to the risk of large bowel cancer: a review of epidemiologic studies," Cancer Letters, vol. 52, no. 3, pp. 163-171, 1990.

[71] L. J. Vatten, K. Solvoll, and E. B. Loken, "Coffee consumption and the risk of breast cancer. A prospective study of 14,593 Norwegian women," British Journal of Cancer, vol. 62, no. 2, pp. 267-270, 1990.

[72] H. R. Ha, J. Chen, S. Krähenbühl, and F. Follath, "Biotransformation of caffeine by cDNA-expressed human cytochromes P450," European Journal of Clinical Pharmacology, vol. 49, no. 4, pp. 309-315, 1996.

[73] H. Y. Chen and G. C. Yen, "Possible mechanisms of antimutagens by various teas as judged by their effects on mutagenesis by 2-amino-3-methylimidazo[4,5-f] quinoline and benzo[a] pyrene," Mutation Research, vol. 393, no. 1-2, pp. 115-122, 1997.

[74] B. Stavric, T. I. Matula, R. Klassen, and R. H. Downie, “The effect of teas on the in vitro mutagenic potential of heterocyclic aromatic amines," Food and Chemical Toxicology, vol. 34, no. 6, pp. 515-523, 1996.

[75] J. H. Weisburger, L. Dolan, and B. Pittman, "Inhibition of PhIP mutagenicity by caffeine, lycopene, daidzein, and genistein," Mutation Research, vol. 416, no. 1-2, pp. 125-128, 1998. 
[76] M. Xu, A. C. Bailey, J. F. Hernaez, C. R. Taoka, H. A. J. Schut, and R. H. Dashwood, "Protection by green tea, black tea, and indole3-carbinol against 2-amino-3-methylimidazo[4,5-f] quinolineinduced DNA adducts and colonic aberrant crypts in the F344 rat," Carcinogenesis, vol. 17, no. 7, pp. 1429-1434, 1996.

[77] T. Kato, S. Takahashi, and K. Kikugawa, "Loss of heterocyclic amine mutagens by insoluble hemicellulose fiber and highmolecular-weight soluble polyphenolics of coffee," Mutation Research, vol. 246, no. 1, pp. 169-178, 1991.

[78] A. J. Alldrick and I. R. Rowland, "Caffeine inhibits hepaticmicrosomal activation of some dietary genotoxins," Mutagenesis, vol. 3, no. 5, pp. 423-427, 1988.

[79] A. J. Alldrick, W. E. Brennan-Craddock, and I. R. Rowland, "Dietary caffeine reduces the genotoxicity of MeIQx in the hostmediated assay in mice," Nutrition and Cancer, vol. 24, no. 2, pp. 143-150, 1995.

[80] A. Bu-Abbas, M. N. Clifford, D. Walker, and C. Ioannides, "Marked antimutagenic potential of aqueous green tea extracts: mechanism of action," Mutagenesis, vol. 9, no. 4, pp. 325-331, 1994.

[81] M. Zdunek, J. Piosik, and J. Kapuscinski, "Thermodynamical model of mixed aggregation of ligands with caffeine in aqueous solution. Part II," Biophysical Chemistry, vol. 84, no. 1, pp. 77-85, 2000.

[82] J. Kapuscinski and M. Kimmel, "Thermodynamical model of mixed aggregation of intercalators with caffeine in aqueous solution," Biophysical Chemistry, vol. 46, no. 2, pp. 153-163, 1993.

[83] M. B. Lyles and I. L. Cameron, "Interactions of the DNA intercalator acridine orange, with itself, with caffeine, and with double stranded DNA," Biophysical Chemistry, vol. 96, no. 1, pp. 53-76, 2002.

[84] M. B. Lyles and I. L. Cameron, "Caffeine and other xanthines as cytochemical blockers and removers of heterocyclic DNA intercalators from chromatin," Cell Biology International, vol. 26, no. 2, pp. 145-154, 2002.

[85] H. Kimura and T. Aoyama, "Decrease in sensitivity to ethidium bromide by caffeine, dimethylsulfoxide or 3-aminobenzamide due to reduced permeability," Journal of PharmacobioDynamics, vol. 12, no. 10, pp. 589-595, 1989.

[86] P. A. Bolotin, S. F. Baranovsky, and M. P. Evstigneev, "Spectrophotometric investigation of the hetero-association of Caffeine and thiazine dye in aqueous solution," Spectrochimica Acta A, vol. 64, no. 3, pp. 693-697, 2006.

[87] M. P. Evstigneev, V. P. Evstigneev, and D. B. Davies, "NMR investigation of the effect of caffeine on the hetero-association of an anticancer drug with a vitamin," Chemical Physics Letters, vol. 432, no. 1-3, pp. 248-251, 2006.

[88] M. P. Evstigneev, K. A. Rybakova, and D. B. Davies, "Complexation of norfloxacin with DNA in the presence of caffeine," Biophysical Chemistry, vol. 121, no. 2, pp. 84-95, 2006.

[89] K. Ulanowska, J. Piosik, A. Gwizdek-Wiśniewska, and G. Wegrzyn, "Formation of stacking complexes between caffeine (1,2,3-trimethylxanthine) and 1-methyl-4-phenyl-1,2,3,6tetrahydropyridine may attenuate biological effects of this neurotoxin," Bioorganic Chemistry, vol. 33, no. 5, pp. 402-413, 2005.

[90] L. Bravo, "Polyphenols: chemistry, dietary sources, metabolism, and nutritional significance," Nutrition Reviews, vol. 56, no. 11, pp. 317-333, 1998.

[91] D. M. Shankel, S. Kuo, C. Haines, and L. A. Mitscher, "Extracellular interception of mutagens," Basic life sciences, vol. 61, pp. 65-74, 1993.
[92] M. M. Manson, "Cancer prevention-the potential for diet to modulate molecular signalling," Trends in Molecular Medicine, vol. 9, no. 1, pp. 11-18, 2003.

[93] T. Nakasugi, M. Nakashima, and K. Komai, "Antimutagens in gaiyou (Artemisia argyi Levl. et Vant.)," Journal of Agricultural and Food Chemistry, vol. 48, no. 8, pp. 3256-3266, 2000.

[94] S. Arimoto-Kobayashi, C. Sugiyama, N. Harada, M. Takeuchi, M. Takemura, and H. Hayatsu, "Inhibitory effects of beer and other alcoholic beverages on mutagenesis and DNA adduct formation induced by several carcinogens," Journal of Agricultural and Food Chemistry, vol. 47, no. 1, pp. 221-230, 1999.

[95] G. J. Soleas, G. Tomlinson, E. P. Diamandis, and D. M. Goldberg, "Relative contributions of polyphenolic constituents to the antioxidant status of wines: development of a predictive model," Journal of Agricultural and Food Chemistry, vol. 45, no. 10, pp. 3995-4003, 1997.

[96] S. Izawa, N. Harada, T. Watanabe et al., "Inhibitory effects of food-coloring agents derived from monascus on the mutagenicity of heterocyclic amines," Journal of Agricultural and Food Chemistry, vol. 45, no. 10, pp. 3980-3984, 1997.

[97] R. Vikse, B. Balsrud Mjelva, and L. Klungsoyr, "Reversible binding of the cooked food mutagen MeIQx to lignin-enriched preparations from wheat bran," Food and Chemical Toxicology, vol. 30, no. 3, pp. 239-246, 1992.

[98] P. Sjodin, M. Nyman, L. L. Nielsen, H. Wallin, and M. Jagerstad, "Effect of dietary fiber on the disposition and excretion of a food carcinogen (2-14C-labeled MeIQx) in rats," Nutrition and Cancer, vol. 17, no. 2, pp. 139-151, 1992.

[99] L. R. Ferguson, A. M. Roberton, M. E. Watson, C. M. Triggs, and P. J. Harris, "The effects of a soluble-fibre polysaccharide on the adsorption of carcinogens to insoluble dietary fibres," ChemicoBiological Interactions, vol. 95, no. 3, pp. 245-255, 1995.

[100] P. Ryden and J. A. Robertson, "The effects of $\mathrm{pH}$ and bile salts on the binding of MeIQx to wheat bran fibre," Mutation Research, vol. 351, no. 1, pp. 45-52, 1996.

[101] P. J. Harris, C. M. Triggs, A. M. Roberton, M. E. Watson, and L. R. Ferguson, "The adsorption of heterocyclic aromatic amines by model dietary fibres with contrasting compositions," Chemico-Biological Interactions, vol. 100, no. 1, pp. 13-25, 1996. 

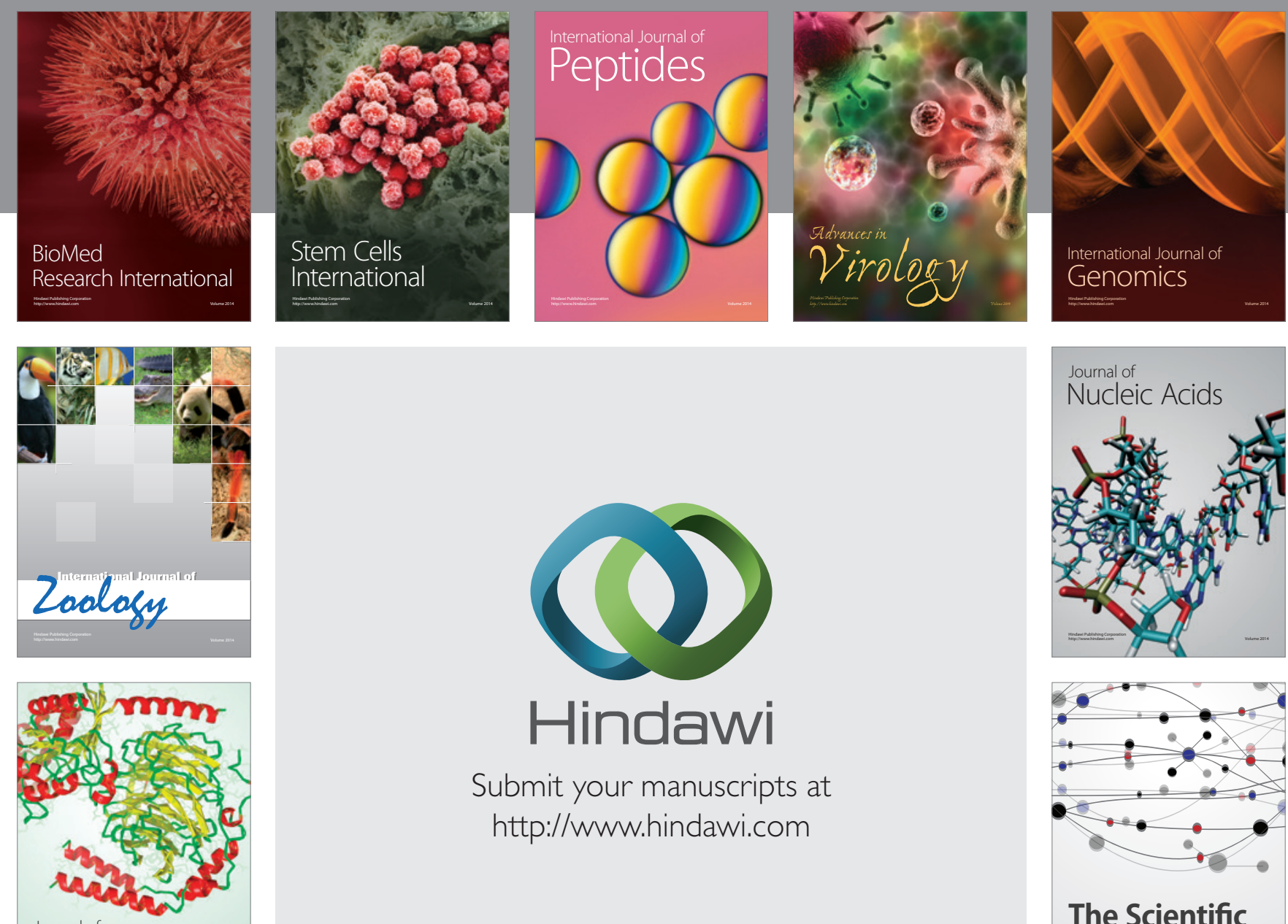

Submit your manuscripts at

http://www.hindawi.com

Journal of
Signal Transduction
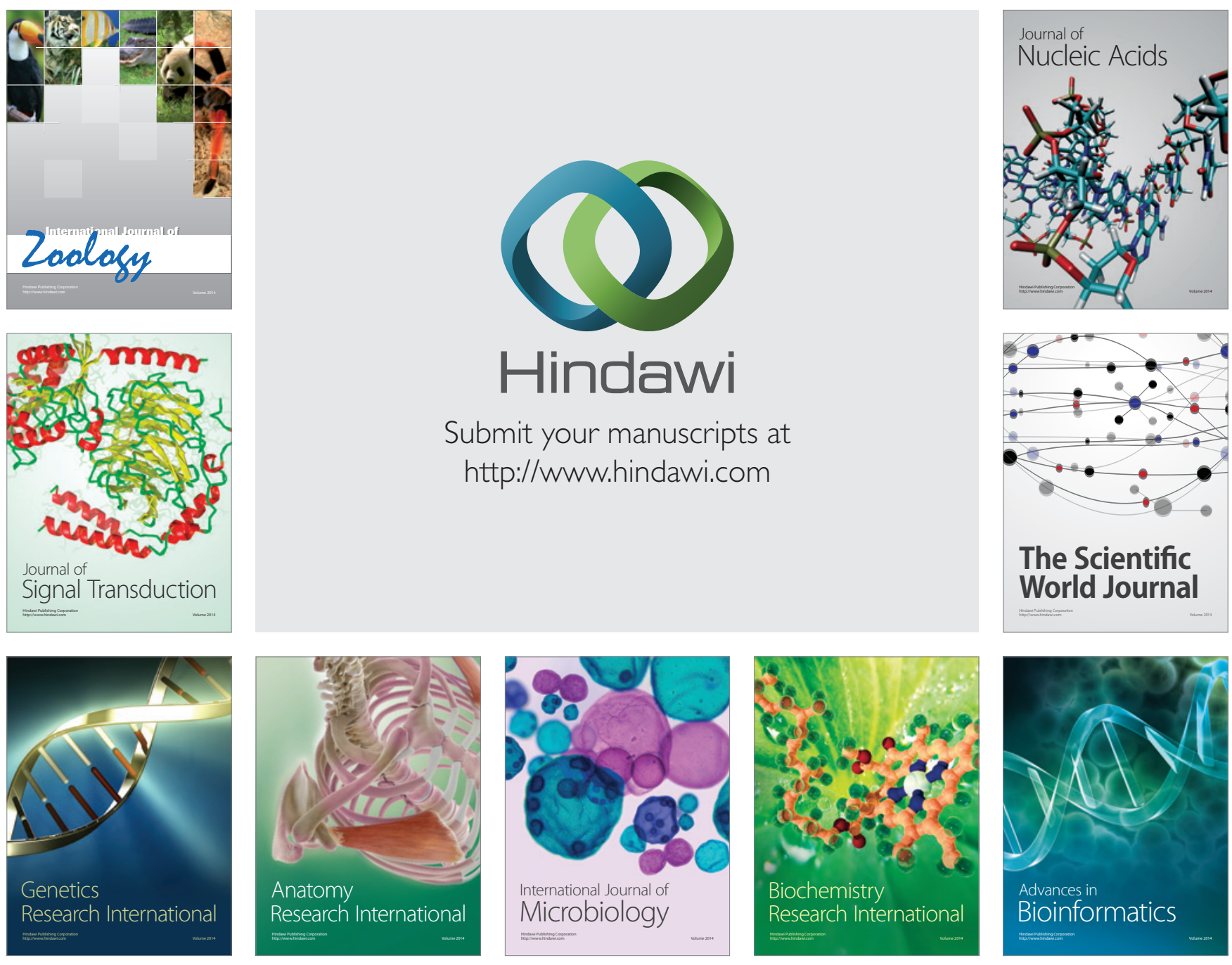

The Scientific World Journal
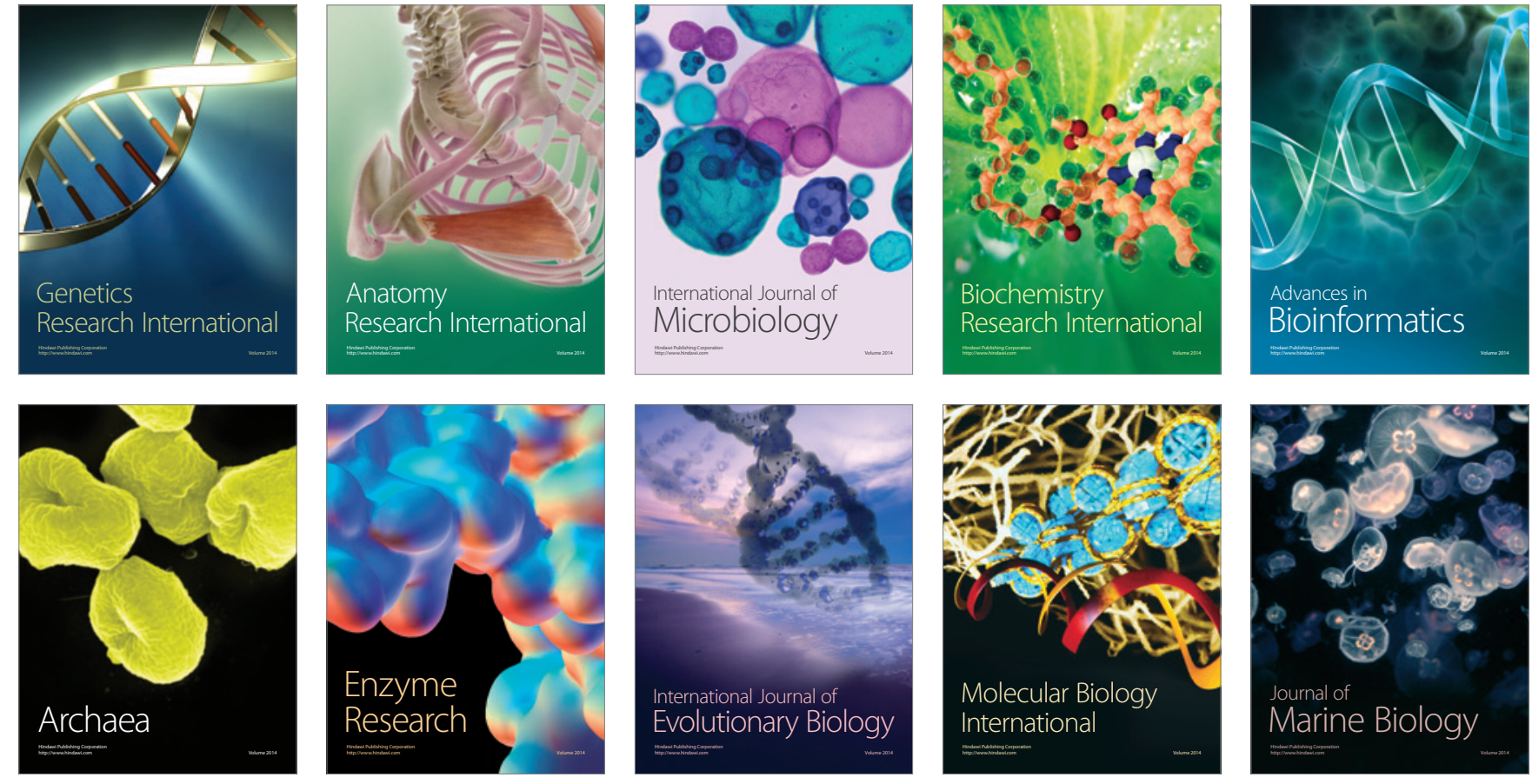